\title{
Aggregation Behavior in Spiderlings: a Strategy for Increasing Life Expectancy in Latrodectus geometricus
} (Araneae: Theridiidae)

\author{
by \\ Ingrid de Carvalho Guimarães ${ }^{1}$; Hermano Marques da Silva \\ $\&$ William Fernando Antonialli Junior ${ }^{1}$
}

\section{ABSTRACT}

Studies on the biology of Latrodectus geometricus are scarce, especially on the behavior and life expectancy of the species. In this study we investigated the importance of the aggregation behavior of juveniles on life expectancy and longevity of the species. Egg sacs were collected in the urban area of DouradosMS and transferred to the laboratory. The spiderlings hatched were separated into two groups: spiderlings aggregated and isolated, kept in the presence of luminosity. The same tests were run with egg sacs deprived of luminosity. A calculation of entropy was performed for all cases. Individuals grouped held under light exposure showed 14.3 days of life expectancy and 46 maximum longevity and 14.8 days of life expectancy and 32 days of longevity when isolated. For individuals grouped and deprived of light life expectancy was 29.8 days and maximum longevity 85 days and 19.3 days of life expectancy and 26 days of maximum longevity when isolated. The entropy of individuals kept in the presence of light, when grouped was $H=0.692$ and when isolated $H=0.377$. For individuals deprived of light, the entropy was $H=0.628$ when kept grouped and $H=0.143$ when isolated. Therefore it is concluded that the aggregation behavior and luminosity influence the longevity and life expectancy of spiderlings. Cannibalism must be a strategy to acquire food reserves contributing to the survival of a small number of individuals.

Keywords: Hourglass spider, cannibalism, survival.

\section{INTRODUCTION}

ThegenusLatrodectus (Walckenaer 1805) (Araneae: Theridiidae), which includes the well-known black-widows, currently comprises 31 species (Platnick

\footnotetext{
${ }^{1}$ Laboratory of Ecology, Center of Integrated Analysis and Environmental Monitoring, State University of Mato Grosso do Sul, Rodovia Dourados / Itahum KM 12, Mailbox 351, 79804-907, Dourados MS, Brazil.guimaraes_ingrid@yahoo.com.br
} 
2007), which are widespread, occurring on multiple continents and islands (Garb et al. 2004). These spiders have nocturnal habits and several members of the genus are synanthropic and can be frequently found in new locations (Andrade 2003; Garb et al. 2004). They are generalist predators, known to feed on insects, crustaceans, other arachnids and even small vertebrates, including lizards and young rats (Forster 1995; Hódar \& Sánchez-Piñero 2002). They have a round abdomen and thin legs; females reach up to $2 \mathrm{~cm}$ in length, while males may achieve only $4 \mathrm{~mm}$ (Cardoso \& Lucas 2003). The egg hatching occurs after approximately 20 days and the females remain near the egg sacs during the first days after hatching, a period in which the spiderlings remain grouped in the natal web and the index of juvenile cannibalism is high (Baerg 1923; Kaston 1968, 1970). After this period, males and females leave the web, the males in search of females for mating and the females seek to disperse from the natal web, living usually alone in their own webs (Kasumovic \& Andrade 2004).

The species L. geometricus (C. L. Koch ), commonly called the Brown Widow, has the least toxic venom of the genus. It is found virtually throughout the Brazilian territory, including human constructions: around and inside houses, gardens, barns and also in agricultural areas (Muller 1993; Eicktedt 1999). These spiders have a varied coloration since greenish to grayish, with orange spots on the dorsal face and an hourglass in the ventral face, usually orange or yellowish, which is why they are also called "hourglass spiders" (Eicktedt 1999; Lucas 2003). Brown Widows can often be found with their egg sacs, which are easily identified by having projections along its entire length (Abalos 1962; Forster \& Kingsford 1983).

Works on L. geometricus are scarce probably due to the low number of accidents involving the species (Levi \& Levi 2002). Most studies focus on biochemical analysis of the toxin of these spiders and their geographical distribution (Garb et al. 2004; Albuquerque et al. 2005; Brown et al. 2008), while studies on the basic biology are rare. However, the knowledge of aspects related to the basic biology and behavior of these spiders are relevant, because the study of these aspects is essential by being the biological key to many issues, and also provide support for further works (Bury 2006).

The study of behavior, for example, is important because it serves as a link between the molecular and physiological aspects of biology and ecology. 
Thus, the behavior is one of the most important properties of animal life, because it represents the aspect of an organism with which it interacts with the environment (Snowdon 1999).

A relatively common behavior in spiders (Busker et al. 1984; Elgar 1992; Elgar \& Schneider 2004) that can ensure greater reproductive success is sexual cannibalism. The most studied case involving complicity of males is the widow spider Latrodectus hasselti (Thorell 1870), whose popular name is "Australian redback", in which males place their abdomen in front of the female chelicerae (somersault behavior) and are consumed during copulation, doubling their reproductive success compared to males who do not perform such behavior (Andrade 1996). According to Segoli et al. (2008) Brown Widows also have shown this behavior, however more studies are needed to help the understanding of the evolution of this extreme form of male monogamy.

Sexual cannibalism is not the only form of cannibalism in spiders. Many studies demonstrate that spiders, in general, cannibalize according to food resource limitation, relatedness, population density, size differences and habitat complexity (Wagner \& Wise 1996, 1997; Samu et al. 1999; Rickers \& Scheu 2005; Wise 2006). The study by Johnson et al. (2010) shows that for $L$. hesperus (Chamberlin \& Ivie 1935) the family origin influences the propensity to cannibalism and that this behavior can be a heritable trait, although there are no genetic data that prove the heredity of cannibalism in any spider taxa. In this context, this study investigated the importance of the aggregation behavior of juveniles on the life expectancy and longevity of this species, perhaps leading to an increase in their reproductive success.

\section{MATERIAL AND METHODS}

To obtain spiderlings and adults for experiments, thirty-two egg sacs of $L$. geometricus and their females were collected in the urban area of DouradosMS ( $\left.22^{\circ} 14^{\prime} S-54^{\circ} 49^{\prime} \mathrm{W}\right)$. The egg sacs were used to identify the specimens, because they have a peculiar conformation that facilitates the identification of the species (Abalos 1962). For greater reliability, the identification was confirmed by Professor Jerome Rovner, from the University of Ohio (USA).

Individuals were transferred to the laboratory where they were individualized in plastic transparent $15 \times 5 \mathrm{~cm}$ containers. The egg sacs collected in natural environments and those produced in the laboratory, totaling $32 \mathrm{egg}$ 
sacs, were measured and then individualized in plastic circular pots of $7 \times 5 \mathrm{~cm}$ in airy locations.

The relative humidity was controlled by moistened cotton placed at the bottom of each pot, as a way to preserve the elasticity of the silk of egg sacs, which may be affected if the habitat is too dry (Work \& Morosoff 1982, Work \& Young 1987; Edmonds \& Vollrath 1992). Data of temperature and relative humidity were registered in two periods of the day, always at 12:00 and 21:00 hours, remaining on average $23.9 \pm 3.6^{\circ} \mathrm{C}$ and relative humidity of $56.3 \pm 10 \%$.

For the experiments, the spiderlings hatched from 10 eggsacs were separated into two groups: 100 spiderlings, from five egg sacs, were kept aggregated in groups of 20, and 100 spiderlings from other five egg sacs were isolated. Both groups were maintained in presence of luminosity.

To assess whether light exposure influences the time of hatching of the spiderlings, as well as the life expectancy, 11 egg sacs were kept in the total absence of light. After hatching the spiderlings were divided again into two situations; 3 groups of 20 spiderlings, from 3 egg sacs, were kept aggregated $(n=60)$ and 60 spiderlings, from the other egg sacs were kept isolated. Both groups were maintained in total absence of light.

Monitoring of spiderlings was done every two days, in order to register the molts, as well as determine the mortality rate of egg sacs in all cases studied.

To build the life table we applied the parameter of Carey (1993), estimated by:

$$
\mathrm{T}_{\mathrm{x}}=\sum_{\mathrm{x}=0}^{\mathrm{w}} \mathrm{L}_{\mathrm{x}}
$$

where $T_{x}=$ total number of days at age $x$ of survivors until the last possible day of life; $x=$ age interval; $n_{x}=$ number of survivors at the beginning of each age interval; $w=$ maximum age in days reached by the last surviving individual; $L_{x}=$ average of probability of survivors between successive ages, calculated as $L_{x}=l_{x}-\left(d_{x}\right) / 2 ; l_{x}=$ proportion of survivors from emergence in relation to age interval; $d_{x}=$ proportion of individuals that died between age $x$ and $x+1$, calculated as $d_{x}=l_{x}-l_{x+1} ; D_{x}=$ number of deaths that occurred during each age interval; $q_{x}=$ probability of death at age $x$, calculated as $q_{x}=$ $\mathrm{d}_{\mathrm{x}} / 1_{\mathrm{x}} ; p x=$ probability of survivors; $p_{x}=1-\mathrm{q}_{\mathrm{x}} ; e_{x}=$ remaining life expectancy 
of individuals at the beginning of each age interval, calculated as $e_{x}=T_{x} / l_{x}$. Life expectancy was calculated to an interval of a day.

The entropy was calculated by the equation:

$$
\mathrm{H}=\sum_{\mathrm{x}=0}^{\mathrm{w}} \mathrm{e}_{\mathrm{x}} \mathrm{d}_{\mathrm{x}} / \mathrm{e}_{0}
$$

Carey (1993) uses the entropy as an estimator of the standard survival in experimental populations, quantitative distribution of mortality according to age. According to him, the value of the entropy curve $I$ is 0.0 , the curve II is 0.5 and the IV curve is 1.0. If all individuals die at exactly the same age, the proportion of survivors $l x$ according to age $x$ would be characterized by a rectangular curve and $H=0$, indicating a hypothetical situation in which all individuals reach the maximum physiological longevity for the species. On the other hand, if all individuals have equal probability of death for every age $x$ (e. g. if all values of $p x$ are identical), the curve $l x$ would decrease linearly and matches $H=0.5$, so mortality would not depend on the age. When $H$ $=1.0$, the pattern of survival would be characterized by high mortality in the initial interval and life expectancy would decrease with age of survival. In this case, survival would decline exponentially with age.

\section{RESULTS AND DISCUSSION}

The egg sacs of L. geometricus have a pyriform aspect, resembling the basic structure of a virus or an armor, and are whitish when just constructed, becoming yellowish with time (Abalos 1962). The egg sacs collected presented diameters between 6.8 and $8.6 \mathrm{~mm}$. Thus, compared with other species of the genus Latrodectus the Brown Widow has one of the smallest egg sacs. $L$. variegatus (Nicolet 1849) and L. corallinus (Abalos 1980) present egg sacs between 14 and $18 \mathrm{~mm}, L$. antheratus (Badcock 1932) between 7 and $10 \mathrm{~mm}$, L. mirabilis (Holmberg 1876) and L. diaguita (Carcavallo 1960) between 15 and $25 \mathrm{~mm}$ (González et al. 1998). On average around $105 \pm 54$ spiderlings were produced per egg sac, less than in $L$. variegatus which presents a number of births around 183 per egg sac (González et al. 1998).

The development time and hatching of the spiderlings from egg sacs submitted to the absence of light was $30 \pm 11$ days, higher than those kept exposed to light which took $25 \pm 9$ days to hatch, demonstrating that the luminosity is a determining factor for the development time and hatching. The hatch- 
ing time of the spiderlings, exposed to light, in this species was lower than in other species of the genus. In L. atritus (Urquhart 1890) the time is 40 days, L. katipo (Powell 1871), 30 days and L. hasselti about 43 days (Forster \& Kingsford 1983).

It was possible to distinguish between males and females by observations on the differentiation of the embolus, in the case of males, and the differentiation of the genital opening in females (epigynum), because these are characteristics that guarantee the precise distinction between the sexes to the naked eye (Levi 1959). Of the total number of spiderlings used in the experiments, the distinction between males and females was possible only in 45 individuals. This low number is due to the fact that it was not possible to identify the sex of individuals who died before the start of the differentiation of the external reproductive organs, because before that, males and females

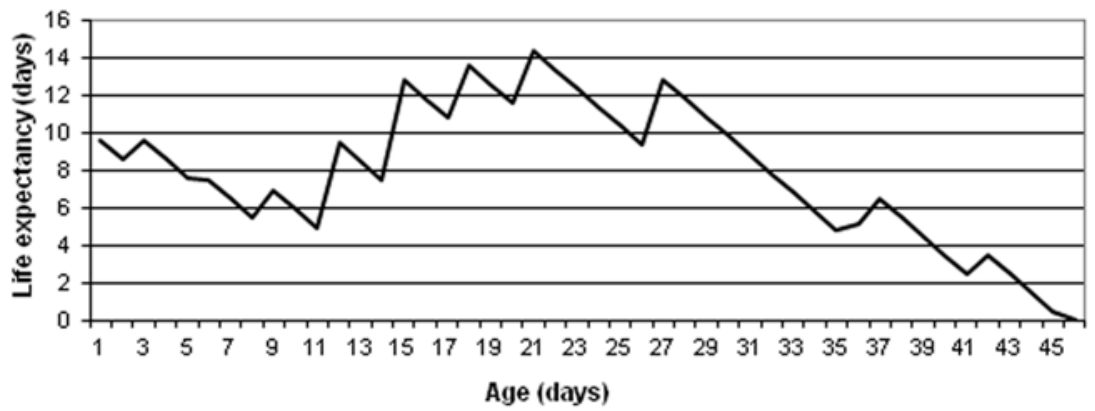

Fig. 1. Life expectancy of spiderlings of $L$. geometricus kept grouped and in the presence of luminosity. Life expectancy of 14.3 days and maximum longevity of 46 days.

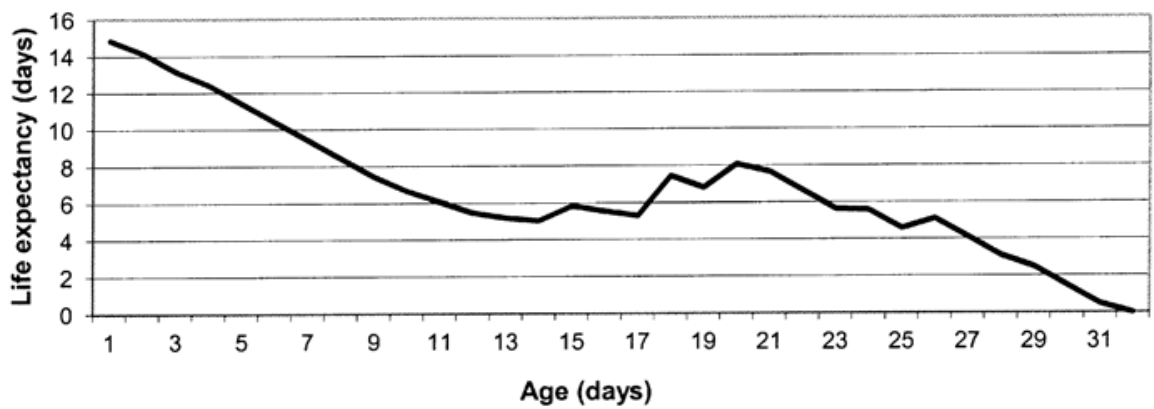

Fig. 2. Life expectancy of spiderlings of $L$. geometricus kept isolated and in the presence of luminosity. Life expectancy of 14.8 days and maximum longevity of 32 days. 
are virtually identical.

Individuals kept under light exposure showed 14.3 days of life expectancy and 46 days of maximum longevity when kept grouped (Fig. 1) and 14.8 days of life expectancy and longevity of 32 days when isolated (Fig. 2). For individuals deprived of light life expectancy was 29.8 days and maximum longevity of 85 days when kept grouped (Fig. 3) and 19.3 days of life expectancy and 26 days of maximum longevity when kept isolated (Fig. 4).

It is noted that when the spiderlings were kept together, both in the presence and absence of light, the rate of cannibalism was high, and although life expectancy decreased in the early days, the longevity of the few survivors wass greater than those that had been individualized, demonstrating that the grouping, which occurs naturally in the first days of life should be an important strategy for the reproductive success of the species (Baerg 1923;

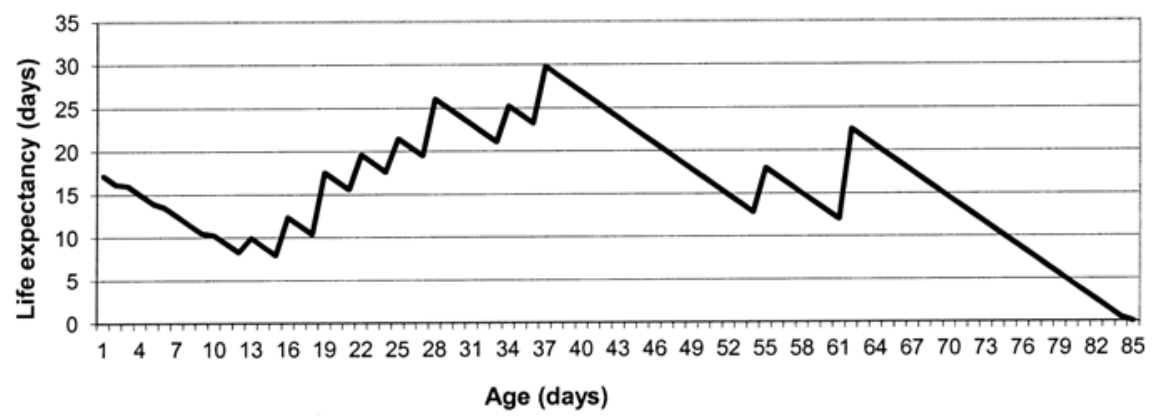

Fig. 3. Life expectancy of spiderlings of $L$. geometricus kept grouped and deprived of light. Life expectancy of 29.8 days and maximum longevity of 85 days.

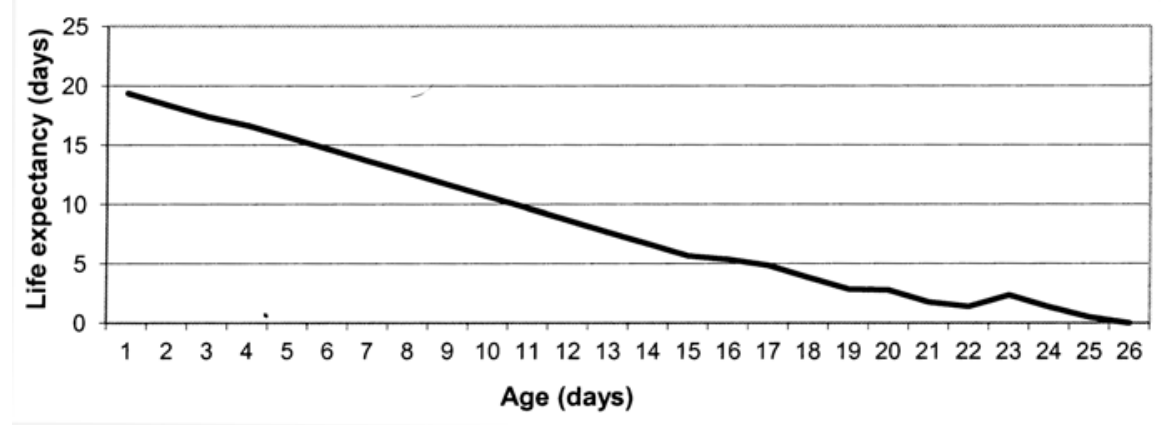

Fig. 4. Life expectancy of spiderlings of L. geometricus kept isolated and deprived of light. Life expectancy of 19.3 days and maximum longevity of 26 days. 


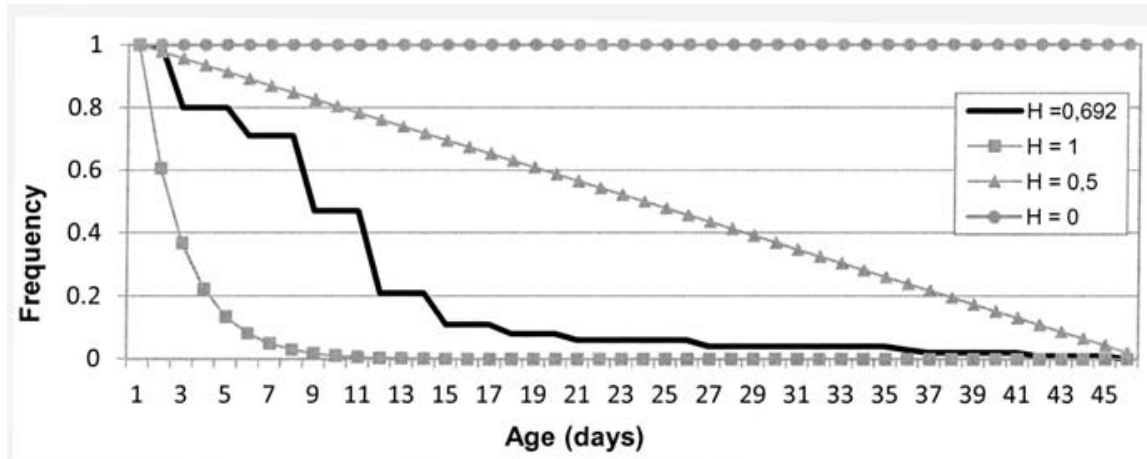

Fig. 5. Entropy analysis for the spiderlings of $L$. geometricus kept grouped and in the presence of light: $H=0.692$.

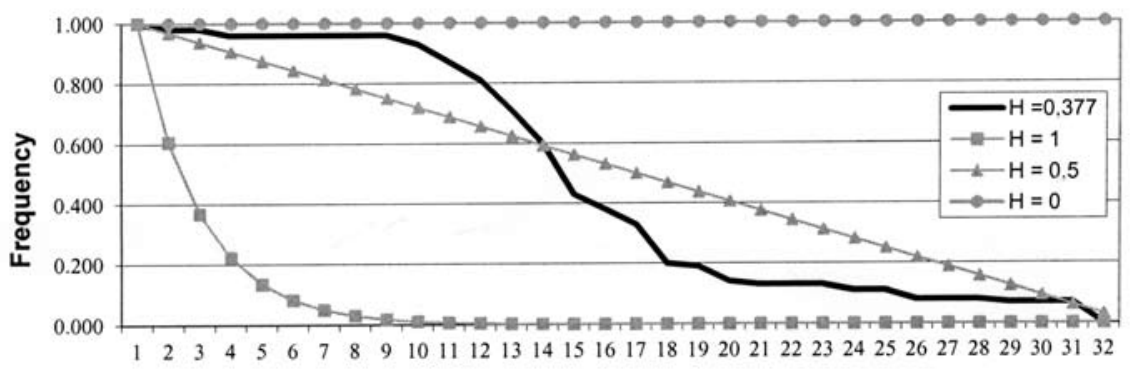

Age (days)

Fig. 6. Entropy analysis for the spiderlings of L. geometricus kept isolated and in the presence of light: $H=0.377$.

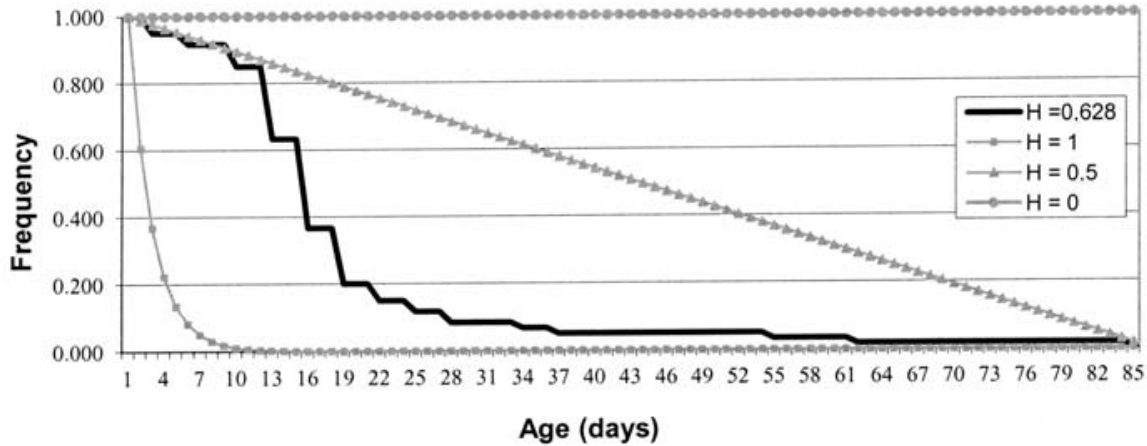

Fig. 7. Entropy analysis for the spiderlings of L. geometricus kept grouped and deprived of light: $H=0.628$. 
Kaston 1968).

The entropy analysis for individuals kept under light exposure showed that when grouped the value of $H$ was 0.692 (Fig. 5) and when isolated individuals presented $H=0.377$ (Fig. 6). For individuals deprived of light, the entropy was $H=0.628$ when kept grouped (Fig. 7 ) and $H=0.143$ when isolated (Fig. 8).

These results show that when spiderlings were kept together, both in the presence and absence of light, the values found, $H=0.692$ and $H=0.628$ respectively, stood between the theoretical values of $H=0.5$ and $H=1.0$, indicating that there was a relatively high mortality rate during the first days of life for both cases. Consequently, the survival curve has a convex aspect during the early days and there is a gradual increase in deaths after this period. However, when isolated, the values found of $H=0.377$ in the presence of light and $H=0.143$ deprived of luminosity, stood between the theoretical values of $H=0$ and $H=0.5$ indicating that the mortality rate in the early days was lower than in previous treatments, however there was a considerable decrease in life expectancy and longevity for these individuals, creating a relatively concave survival curve pattern.

Even under experimental conditions, the results corroborate other studies, which underscore the importance of cannibalism among spiderlings of Latrodectus to the reproductive success of the species, even when there is food availability (Baerg 1923; Kaston 1968). Therefore, in contrast with some authors who suggest that cannibalism can be an accidental consequence as a result of

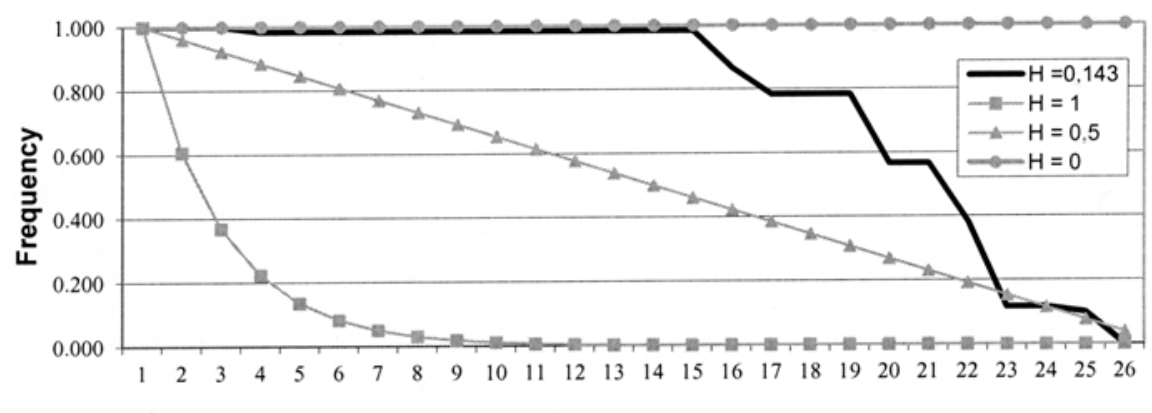

Age (days)

Fig. 8. Entropy analysis for the spiderlings of L. geometricus kept isolated and deprived of light: $H=0.143$. 
competition for prey (Forster 1995) perhaps cannibalizing individuals is an additional strategy to acquire food reserves and thus contribute to survival of at least a small number of individuals, a common strategy by several animals (Polis 1981 and references cited there; Belles \& Fitzgerald 1993; Giray et al. 2001; Johnson 2001). In a study with L. hesperus, Johnson et al. (2010), suggested that cannibalism among spiderlings may be a genetically heritable character, acting as an adaptive strategy of foraging, developed by spiderlings from egg sacs that share a poorly provisioned maternal environment.

As noticed, luminosity, apart from the time of hatching, also affects the development of the spiderlings. Individuals maintained grouped presented the highest median longevity (Figs. 1 and 3), however, those who were kept in the absence of light reached higher longevity (Fig. 3). Few studies have investigated the influence of luminosity during development of spiderlings on longevity, although it is known that the molting process can be influenced by sexual, nutritional, hormonal and genetic characteristics (Forster \& Kingsford 1983; Nentwig 1987).

Thus, under the conditions evaluated in this work, it can be inferred that the aggregation behavior inducing spiderlings to cannibalism and also the incidence of light influence the longevity and life expectancy and probably increase the reproductive success of the species.

\section{ACKNOWLEDGMENT}

WFAJ acknowledges research support from CNPq.

\section{REFERENCES}

Abalos, J.W. 1962. The Egg-sac in the Identification of Species of Latrodectus (Black-Widow Spiders). Psyche 69:268-270.

Albuquerque, H.N., I.C.S. Albuquerque, A. Ribeiro \& I.R. Menezes. 2005. Presença de Latrodectus geometricus C.L. Koch, 1841 e Latrodectus curacaviensis Müller, 1776 (Araneae, Theridiidae) em Campina Gande-PB. Revista de Biologia e Ciências da Terra 5:0.

Andrade, M.C.B. 1996. Sexual selection for male sacrifice in the Australian redback spider. Science 271:70-72.

Andrade, M.C.B.2003. Risky mate search and male self-sacrifice in redback spiders. Behavioral Ecology 14:531-538.

Baerg, W.J. 1923. The black widow: its life history and the effects of its poison. Science 


$$
\text { Guimarães, I.C. et al. - Aggregation Behavior in Spiderlings }
$$

Monthly 17:535-547.

Belles, I.J.C. \& G.J. Fitzgerald. 1993. A fitness advantage of cannibalism in female sticklebacks (Gasterosteus aculeatus L.). Ethology Ecology \& Evolution 5:187-191.

Brown, K.S., J.S. Necaise \& J. Goddard. 2008. Additions to the Known U.S. Distribution of Latrodectus geometricus (Araneae: Theridiidae). Journal of Medical Entomology 45:959-962.

Bury, R.B. 2006. Natural History, Field Ecology, Conservation Biology and Wildlife Management: Time to connect the dots. Herpetological Conservation and Biology 1:53-61.

Buskirk, R.E., C. Frohlich \& K.G. Ross. 1984. The natural selection of sexual cannibalism. American Naturalist 123:612-625.

Cardoso,J.L.C. \& S.M.Lucas. 2003. Introdução ao araneísmo.p. 139-149. In:J.L.C. Cardoso, F.O.S. França, F.H. Wen, C.M.S. Málaque \& V. Haddad Jr. Animais Peçonhentos no Brasil: Biologia, Clínica e Terapêutica dos Acidentes. Sarvier, São Paulo.

Carey, J.R. 1993. Applied demography for biologists. Oxford University Press, New York. $206 \mathrm{p}$.

Edmonds, D.T \& F. Vollrath. 1992. The contribution of atmospheric water vapour to the formation and efficiency of spider's capture web. Proceedings of the Royal Society B: Biological Sciences 248:145-148.

Eicktedt, V.R.V. 1999. Aranhas de Importância Médica no Brasil.p.261-298. In: B. Barraviera. Venenos: Aspectos Clínicos e Terapêuticos dos Acidentes por Animais Peçonhentos. EPUB, Rio de Janeiro.

Elgar, M.A. 1992. Sexual cannibalism in spiders and other invertebrates. p. 128-155. In: M.

Elgar \& B. Crespi. Cannibalism Ecology and Evolution Among Diverse Taxa. Oxford University Press, Oxford.

Elgar,M.A. \&J.M.Schneider. 2004. Evolutionary significance of sexual cannibalism. Advances in the Study of Behavior 34:135-163.

Forster, L. \& S. Kingsford. 1983. A preliminary study of development in two Latrodectus species (Araneae: Theridiidae). New Zealand Entomology 7:431-439.

Forster, L.M. 1995. The behavioral ecology of Latrodectus hasselti (Thorell), the Australian redback spider (Araneae: Theridiidae): a review. Records of Western Australian Museum Supplement 52:13-24.

Garb, J.E., A. González \& R.G. Gillespie. 2004. The black widow spider genus Latrodectus (Araneae: Theridiidae): phylogeny, biogeography, and invasion history. Molecular Phylogenetics and Evolution 31:1127-1142.

Giray, T., Y.A. Luyten, M. MacPherson \& L. Stevens. 2001. Physiological bases of genetic differences in cannibalism behavior of the confused flour beetle Tribolium confusum. Evolution 55:797-806.

González, A., S. González \& A. Armendano. 1998. Desarrollo postembrionariodeLatrodectus variegatus (Araneae: Theridiidae). Revista de Biología Tropical 46:93-99.

Hódar,J.A \& F. Sánchez-Piñero. 2002. Feeding habitats of the black widow spider Latrodectus 
lilianae (Araneae: Theridiidae) in an arid zone of south-east Spain. Journal of Zoology 257:101-109.

Johnson, J.C. 2001. Sexual cannibalism in fishing spiders (Dolomedes triton): an evaluation of two explanations for female aggression towards potential mates. Animal Behavior 61:905-914.

Johnson, J.C., K. Kitchen \& M.C.B. Andrade. 2010. Family Affects Sibling Cannibalism in the Black Widow Spider, Latrodectus Hesperus. Ethology 116:770-777.

Kaston, B.J. 1968. Remarks on black widow spiders with an account of some anomalies. Entomological News 79:113-124.

Kaston, B.J. 1970. Comparative biology of American black widow spiders. San Diego Society of Natural History Transactions 16:33-82.

Kasumovic, M.M. \& M.C.B. Andrade. 2004. Discrimination of airborne pheromones by mate searching male western black widow spiders (Latrodectus hesperus): species- and population- specific responses. Canadian Journal of Zoology 82:1027-1034.

Levi, H.W. 1959. The Spider Genus Latrodectus (Araneae, Theridiidae). Transactions of the American Microscopical Society 78:7-43.

Levi, H.W \& L.R. Levi. 2002. Spiders and Their Kin. S.t. Martin's Press, New York. 160 p.

Lucas, S.M. 2003. Aranhas de interesse médico no Brasil. p. 139-149. In: J.L.C. Cardoso, F.O.S. França, F.H. Wen, C.M.S. Málaque \& V. Haddad Jr. Animais Peçonhentos no Brasil: Biologia, Clínica e Terapêutica dos Acidentes. Sarvier, São Paulo.

Muller, G.J. 1993. Black and brown widow spider bites in South Africa a series of 45 cases. South African Medical Journal 83:399-405.

Nentwig, W. 1987. Ecophysiology of Spiders. Springer-Verlag, Berlin. 448 p.

Platnick, N.I. 2007. The world spider catalog, version 7.5. American Museum of Natural History, New York. Online at http://research.amnh.org/entomology/spiders/catalog/ index.html

Polis, G.A. 1981. The evolution and dynamics of intraspecific predation. Annual Review of Ecological Systems 12:225-251.

Rickers, S. \& S. Scheu. 2005. Cannibalism in Pardosapalustris (Araneae, Lycosidae): effects of alternative prey, habitat structure, and density. Basic and Applied Ecology 6:471-478.

Segoli, M., R. Arieli, P. Sierwald, A.R. Harari \& Y. Lubin. 2008. Sexual Cannibalism in the Brown Widow Spider (Latrodectus geometricus). Ethology 114:279-286.

Samu, F., S. Toft \& B. Kiss. 1999. Factors influencing cannibalism in the wolf spider Pardosa agrestis (Araneae, Lycosidae). Behavioral Ecology and Sociobiology 45: 349-354.

Snowdon, C.T. 1999. O significado da pesquisa em Comportamento Animal. Estudos de Psicologia 4:365-373.

Wagner, J.D. \& D.H. Wise. 1996. Cannibalism Regulates Densities of Young Wolf Spiders: Evidence From Field and Laboratory Experiments. Ecology 77:639-652.

Wagner, J.D. \& D.H. Wise. 1997. Influence of prey availability and conspecifics on patch 


$$
\text { Guimarães, I.C. et al. - Aggregation Behavior in Spiderlings }
$$

quality for a cannibalistic forager: laboratory experiments with the wolf spider Schizocosa. Oecologia 109:474-482.

Wise, D.H.2006. Cannibalism, food limitation, intraspecific competition, and the regulation of spider populations. Annual Review of Entomology 51:441-465.

Work, R.W. \& N. Morosoff. 1982. A physicochemical study of super contraction of spider major ampullate silk fibers. Textile Research Journal 52:349.

Work, R.W. \& C.T. Young. 1987. The amino acid compositions of major and minor ampullate silks of certain orb-web building spiders (Araneae, Araneidae).The Journal of Arachnology 15:65-80. 
